\title{
Decline in adolescent treatment admissions for methamphetamine use in Cape Town
}

\author{
A Plüddemann, ${ }^{1} \mathrm{PhD} ; \mathbf{S}$ Dada, ${ }^{1} \mathrm{MPH} ; \mathbf{C}$ Parry, ${ }^{1,2} \mathrm{PhD}$ \\ ${ }^{1}$ Alcohol and Drug Abuse Research Unit, South African Medical Research Council, Cape Town, South Africa \\ ${ }^{2}$ Department of Psychiatry, Stellenbosch University, Stellenbosch, South Africa
}

Corresponding author: A Plüddemann (apluddem@mrc.ac.za)

\begin{abstract}
Background and objectives. The purpose of this report is to describe the changing trends in adolescent treatment admissions for methamphetamine in Cape Town, and to discuss possible implications.

Method. Data were collected on admissions for drug abuse treatment through a regular monitoring system involving drug treatment centres and programmes in Cape Town, every 6 months as part of the South African Community Epidemiology Network on Drug Use (SACENDU). A one-page form was completed by treatment centre personnel for each patient to collect demographic and substance abuse data.

Results. The results indicate that between 2004 and 2006, a significant increase in the proportion of adolescent treatment admissions for methamphetamine abuse occurred, while a significant decrease occurred between 2006 and 2011.

Conclusions. The initial increase in adolescent treatment admissions for methamphetamine abuse from 2004 to 2006, and subsequent decrease between 2006 and 2011, may suggest a change in methamphetamine abuse patterns among adolescents in Cape Town.

S Afr Med J 2013;103(7):478-480. DOI:10.7196/SAMJ.6529
\end{abstract}

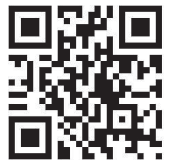

The 2011 United Nations World Drug Report identified South Africa (SA) as one of the countries still experiencing 'some increase' in the use of 'undefined amphetamines'. Other countries and regions included were Australia and SouthEast Asia. ${ }^{[1]}$ In SA, the major contributor to an increase in the use of amphetamine-group substances has been an increase in consumption of methamphetamine in Cape Town and the surrounding Western Cape Province, documented via admissions to treatment centres and surveys among adolescents attending high schools. ${ }^{[2-5]}$ These studies indicated an increase in admissions to specialist substance abuse treatment centres for methamphetamine abuse from $<1 \%$ of patients in 2002 , to $42 \%$ in the second half of 2006. High school surveys conducted between 2005 and 2008 indicated a lifetime prevalence of methamphetamine use among learners of between $9 \%$ and $13 \%$. $^{[2-5]}$

The purpose of this report is to describe changes in adolescent treatment admissions for methamphetamine-related problems in Cape Town between 2004 and 2011, and to discuss the implications.

\section{Methods}

\section{Study design}

Established in 1996, the South African Community Epidemiology Network on Drug Use (SACENDU) is a network of researchers, practitioners and policymakers from 6 regions in SA who meet bi-annually to share community-level public health surveillance information about alcohol and other drug (AOD)-related trends. All AOD treatment centres are invited to volunteer to join the network. SACENDU collects data from more than $80 \%$ of treatment centres in Western Cape Province (most based in Cape Town) and includes state-funded, private non-profit, and private for-profit facilities in its network. Data therefore reflect the activities of treatment centres in the region. The focus of this paper is data obtained from between 23 and 27 specialist substance abuse treatment centres between 2004 and 2011. (The number of centres declined slightly over the 7 years, as a few small centres closed.)

\section{Instruments}

For the purpose of monitoring, a standardised 1-page form is completed for each person treated by a given centre during a 
particular 6-month period. The form records responses concerning the source of referral for treatment, biographical information, the type of treatment received (in- and/or outpatient), the primary and secondary substances of abuse (including alcohol, over-the-counter and prescription medicines, and illicit drugs), the mode(s) of use, frequency of use, age at first use and whether the person had received treatment prior to the current episode. The form is based on the instrument developed by the Pompidou Group in Europe in the early 1990s and, more recently, on the Treatment Demand Indicators (TDI) used by the European Monitoring Centre for Drugs and Drug Addiction. ${ }^{[6]}$ To ensure data quality, treatment centre personnel regularly receive training in data collection, and completed forms are checked for missing information and possible miscoding. Forms are completed by treatment centre personnel upon admission or shortly thereafter.

\section{Ethics}

Ethical approval for this study was provided by the South African Medical Research Council's Ethics Committee and the University of Stellenbosch's Health Research Ethics Committee. The study is a record review, and consent from patients was therefore not required.

\section{Data analysis}

Data were analysed using IBM SPSS version 20 and SAS. The Cochran-Armitage trend test was used to test for significant trends over time.

\section{Results}

Fig. 1 indicates that the proportion of adolescents (i.e. patients $<20$ years old) seeking treatment with methamphetamine as their primary substance of abuse increased steadily from $24.2 \%$ in the first half of $2004(n=138 / 571)$ to $60.2 \%$ in the first half of 2006 $(n=436 / 724)$. This proportion, however, steadily began to decline from the second half of 2006 (58.6\%: $n=446 / 761$ ) to the second half of 2011 (24.5\%: $n=105 / 429)$. The Cochran-Armitage Trend test showed this decrease to be significant $(\mathrm{z}=-20.06, p<0.0001)$. Notably, during the same time period, the proportion of adult patients $(\geq 20$ years old) reporting methamphetamine as their primary substance of abuse increased significantly from $28.7 \%(n=551 / 1927)$ in the first half of 2006 to $41.5 \%$ ( $n=949 / 2288)$ in the second half of 2011 $(\mathrm{z}=7.19, p<0.0001)$.

Between 2006 and 2011, the total number of adolescent and adult patients admitted to treatment centres during each 6-month period remained fairly constant, generally ranging between 2600 and 2900 patients. Table 1 shows the proportions (as percentages) of different primary drugs reported by adolescent patients between 2006 and 2011. The decline in methamphetamine as a primary substance of abuse was accompanied by a proportional increase in abuse of cannabis, and not other 'hard drugs'. First-time admissions for adolescent patients remained between $80 \%$ and $93 \%$ of all admissions between 2006 and 2011, leaving fairly low numbers of previously treated patients.



Fig. 1. Proportions of patients reporting methamphetamine as a primary substance of abuse by 6-monthly reporting period: patients aged $\leq 19$ (youth) v. patients aged $\geq 20$ (adults).

Table 1. Primary substances of abuse for patients $<20$ years old - Western Cape (\%)

\begin{tabular}{|c|c|c|c|c|c|c|c|c|c|}
\hline Period & Alcohol & Cannabis & Cannabis/mandrax & Cocaine/crack & Heroin & Ecstasy & Methamphetamine & Other & Total $(N)$ \\
\hline $04 a$ & 5.1 & 33.1 & 23.3 & 3.7 & 8.2 & 0.9 & 24.9 & 1.1 & 571 \\
\hline $04 \mathrm{~b}$ & 2.3 & 24.4 & 17.6 & 2.9 & 8.6 & 0.6 & 42.0 & 1.6 & 619 \\
\hline $05 a$ & 2.5 & 24.5 & 9.3 & 1.9 & 11.5 & 0.8 & 48.7 & 0.9 & 637 \\
\hline 05b & 3.1 & 22.1 & 6.7 & 1.3 & 12.9 & 0.4 & 53.0 & 0.0 & 674 \\
\hline $06 a$ & 1.7 & 17.4 & 3.9 & 0.6 & 15.3 & 0.0 & 60.2 & 1.0 & 724 \\
\hline 06b & 2.9 & 26.0 & 2.6 & 0.4 & 7.1 & 0.0 & 58.6 & 0.1 & 761 \\
\hline $07 a$ & 3.6 & 24.4 & 2.4 & 0.6 & 9.6 & 0.1 & 56.5 & 0.0 & 803 \\
\hline $07 \mathrm{~b}$ & 5.0 & 35.1 & 3.7 & 0.5 & 11.1 & 0.0 & 43.2 & 1.4 & 812 \\
\hline $08 \mathrm{a}$ & 5.0 & 33.1 & 3.5 & 0.6 & 10.1 & 0.2 & 45.5 & 0.0 & 622 \\
\hline 08b & 3.3 & 42.8 & 2.3 & 2.3 & 7.6 & 0.0 & 39.1 & 2.6 & 657 \\
\hline $09 a$ & 5.0 & 39.6 & 3.3 & 0.3 & 6.3 & 0.0 & 42.4 & 0.0 & 902 \\
\hline $09 \mathrm{~b}$ & 5.9 & 45.7 & 2.0 & 0.5 & 7.5 & 0.0 & 36.1 & 0.0 & 615 \\
\hline $10 \mathrm{a}$ & 6.9 & 45.4 & 5.4 & 0.3 & 6.6 & 0.1 & 33.3 & 0.0 & 702 \\
\hline $10 \mathrm{~b}$ & 14.6 & 38.2 & 4.6 & 0.5 & 7.2 & 0.0 & 33.1 & 1.8 & 610 \\
\hline $11 \mathrm{a}$ & 6.5 & 60.5 & 2.6 & 0.3 & 3.5 & 0.0 & 25.3 & 1.3 & 620 \\
\hline $11 \mathrm{~b}$ & 4.9 & 58.3 & 2.6 & 0.5 & 7.0 & 0.0 & 24.5 & 2.3 & 429 \\
\hline
\end{tabular}




\section{Discussion}

The data analysed in this survey indicate a significant decline in adolescent patients reporting methamphetamine as a primary substance of abuse between 2006 and 2011. Over the same period, a more gradual but significant increase in the proportion of adult patients reporting methamphetamine as a primary substance of abuse was observed. High school surveys conducted in Cape Town or Western Cape Province between 2005 and 2008 indicated selfreported lifetime prevalence of methamphetamine use of between $9 \%$ and $13 \% \cdot{ }^{[3-5]}$ However, a random survey of 227000 high school students in the Western Cape in 2011 found a lifetime prevalence of only $2 \%$, with consistent proportions across the various 'school districts' within the province. ${ }^{[7]}$

Similar trends have been found in some other countries. A study in Canada found a decline in primary methamphetamine-related admissions to youth residential substance abuse treatment facilities. Comparing the years 2005 - 2006 and 2009 - 2010, the authors found that the estimated proportion of youth admissions to inpatient substance abuse treatment centres, primarily owing to methamphetamine, declined from $21 \%$ in $2005-2006$ to $6 \%$ in $2009-2010 .{ }^{[8]}$

The decline was hypothesised as resulting from changes in government policy and legislation concerning regulation of precursor chemicals and an accompanying increase in law enforcement. By comparison, proportions of adolescent patients admitted for treatment in the USA were relatively low between 2006 and 2010, with $3.8 \%$ of patients aged $12-17$ years admitted for amphetamines (including methamphetamine) in 2006, but gradually declining to $2.6 \%$ in 2010 ${ }^{[9]}$ In Australia, treatment for amphetamines constituted only $7 \%$ of all treatment episodes in 2009/2010 and showed a slight decline between 2006 and 2010. In 2009/2010, <5\% of treatment episodes for 10 - 19-year-olds were related to amphetamines. ${ }^{[10]}$

The fact that, in the present study, the decline in adolescent treatment admissions for methamphetamine was accompanied by an increase in the proportion of adolescent patients reporting cannabis as their primary drug, and not other 'hard drugs', is encouraging, as cannabis is considered less harmful than methamphetamine.

Over the period reported, efforts at addressing the abuse of methamphetamine included general information campaigns on the dangers of the drug, media coverage of methamphetamine-related crimes (that are often violent), and reports of increasing arrests for possession and dealing in methamphetamine. Interestingly, it appears that while this may have resulted in a downward trend of adolescent methamphetamine-related treatment admissions, the proportion of adult admissions continued to increase gradually. Foxcroft and Tsertsvadze ${ }^{[11]}$ recently conducted three Cochrane systematic reviews on universal alcohol absuse prevention programmes for children and adolescents, and found that some universal interventions, particularly multi-component interventions, were effective in reducing alcohol consumption. Although alcohol and methamphetamine may not be entirely comparable, adolescents may be more susceptible to universal prevention messages aimed at adolescent substance use.

It remains a concern that the proportion of adult patients admitted for methamphetamine has continued to increase gradually since 2006, suggesting a need for further intervention strategies that specifically target adults.

A limitation of this study was that it relied mainly on a single data source (although supported by high school surveys), and other data such as adolescent arrest data, presentations to trauma or psychiatric units at hospitals, or data from other health practitioners (e.g. general practitioners) could not be accessed as they are not routinely available in SA.

In conclusion, our findings indicate a significant decline in adolescent treatment admissions for methamphetamine abuse. This is an encouraging trend, and may suggest that preventive interventions are particularly effective among adolescents, who are a particularly vulnerable group. Further research is needed to establish the reasons behind the decline and which components of the prevention strategy have been most effective.

Acknowledgments. The authors thank the South African National Department of Health (Mental Health and Substance Abuse Directorate) for their funding of this project, and all the staff at participating substance abuse treatment centres for regularly submitting data.

\section{References}

1. United Nations Office on Drugs \& Crime (UNODC). World Drug Report 2011. Vienna: UNODC, 2011. 2. Plüddemann A, Myers BJ, Parry CD. Surge in treatment admissions related to methamphetamine use in Cape Town, South Africa: Implications for public health. Drug Alcohol Rev 2008;27:185-189. [http://dx.doi.org/10.1080/09595230701829363]

3. Plüddemann A, Flisher AJ, Mathews C, Carney T, Lombard C. Adolescent methamphetamine use and 3. Plüddemann A, Flisher AJ, Mathews C, Carney T, Lombard C. Adolescent methamphetamine use and
sexual risk behaviour in secondary school students in Cape Town, South Africa. Drug Alcohol Rev

4. Plüddemann A, Flisher AJ, McKetin R, Parry C, Lombard C. Methamphetamine use, aggressive behavior and other mental health issues among high-school students in Cape Town, South Africa. Drug Alcohol Depend 2010;109:14-19. [http://dx.doi.org/10.1016/j.drugalcdep.2009.11.021]

5. Reddy P, James S, Sewpaul R, et al. Umthente Uhlaba Usamila - The South African Youth Risk Behaviour Survey 2008. Cape Town: Medical Research Council, 2010.

6. Simon R, Donmall M, Hartnoll R, et al. The EMCDDA/Pompidou Group treatment demand indicator protocol: A European core item set for treatment monitoring and reporting. Eur Addict Res 1999;5:197-207. [http://dx.doi.org/10.1159/000018994]

7. Morojele N, Myers B, Townsend L, et al. Survey on Substance Use, Risk Behaviour and Mental Health among Grade 8-10 Learners in Western Cape Provincial Schools. Cape Town: Medical Research Council, 2012.

8. Verdichevski M, Burns R, Cunningham JK, Tavares J, Callaghan RC. Trends in primary methamphetamine-related admissions to youth residential substance abuse treatment facilities in Canada, 2005-2006 and 2009-2010. Can J Psychiatry 2011;56:696-700.

9. Substance Abuse \& Mental Health Services Administration. Treatment Episodes Data Set (TEDS), 9. Substance Abuse \& Mental Health Services Administration. Treatment Episodes Data Set (THES
United States. http://wwwdasis.samhsa.gov/webt/newmapvl.htm (accessed 27 September 2012).

10. Australian Institute of Health and Welfare. Alcohol and other Drug Treatment Services in Australia 2009-2010: Report on the National Minimum Dataset. Drug Treatment Series no. 14. Cat. no. HSE 114. Canberra: Australian Institute of Health and Welfare, 2011.

11. Foxcroft DR, Tsertsvadze A. Universal alcohol misuse prevention programmes for children and adolescents: Cochrane systematic reviews. Perspect Public Health 2012;132:128-134. [http://dx.doi. org/10.1177/1757913912443487]

Accepted 17 January 2013 